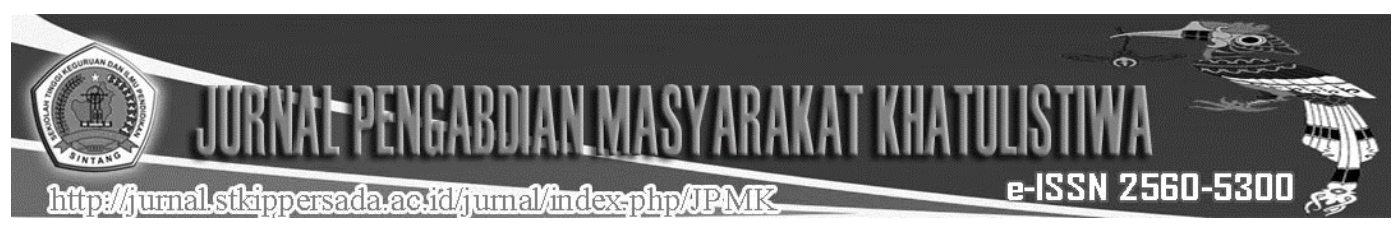

\title{
PKM STRATEGI PENYUSUNAN DAN PENGAJUAN KEKAYAAN INTELEKTUAL
}

Titin

Prodi Pendidikan Biologi FKIP, Universitas Tanjungpura

Email: titin@fkip.untan.ac.id

\begin{abstract}
Intellectual Property for universities is very important, because it can strengthen accreditation, academic processes, community empowerment, and sources of information, as well as foster the pride of the college itself. To encourage increased intellectual property in tertiary institutions, active roles from various parties, namely lecturers and students are needed. During this time, from the results of research and community service produced by lecturers and students, the Biology Education Study Program which contains publications in the form of articles that are disseminated and published in scientific journals. Only a few are made as a result of Intellectual Property and their numbers are very few. For this reason, it is necessary to look for alternatives in the context of research down streaming, and use research / community service for Intellectual Property to increase the intellectual property index of the Biology Education Study Program of FKIP Tanjungpura University. One alternative that can be done is through Community Service preparation of strategies and submissions of Intellectual Property. The method used is socialization and assistance. Study Strategies and mentoring for students of Biology Education Study Program FKIP Tanjungpura University. The activities carried out received positive responses from all participants who received benefits and some were interested in carrying out the proposed IP application independently.
\end{abstract}

Keywords: Intellectual Property, Research Results, Strategy, Biology Education

\begin{abstract}
Abstrak: Kekayaan Intelektual bagi perguruan tinggi itu sangat penting, sebab bisa memperkuat akreditasi, proses akademik, pemberdayaan masyarakat, dan sumber informasi, serta menumbuhkan kebanggaan perguruan tinggi itu sendiri. Untuk mendorong peningkatan kekayaan intelektual di Perguruan Tinggi dibutuhkan peran aktif berbagai pihak, yakni dosen dan mahasiswa.Selama ini luaran dari hasil penelitian dan pengabdian kepada masyarakat yang dihasilkan oleh dosen dan mahasiswa Program studi pendidikan biologi berupa publikasi dalam bentuk artikel yang diseminarkan maupun diterbitkan dalam jurnal ilmiah. Hanya beberapa yang luaran tersebut dijadikan sebagai hasil Kekayaan Intelektual dan jumlahnyapun sangat sedikit. Untuk itu perlu dicari alternatif dalam rangka hilirisasi riset, dan pemanfaatan hasil riset/pengabdian masyarakat berpotensi sebagai kekayaan intelektualguna meningkatkan indeks kekayaan intelektual Program Studi Pendidikan Biologi FKIP Universitas Tanjungpura. Salah satu alternatif yang dapat dilakukan adalah dengan melalui Pengabdian Kepada Masyarakat strategi penyusunan dan pengajuan Kekayaan Intelektual. Metode yang digunakan adalah sosialisasi dan pendampingan strategi penyusunan dan pendampingan kepada dosen dan mahasiswa Program Studi Pendidikan Biologi FKIP Universitas Tanjungpura. Kegiatan yang dilakukan mendapatkan respon positif dimana seluruh peserta menyatakan bermanfaat dan sebagian tertarik untuk melakukan rencana pengajuan KI secara mandiri.
\end{abstract}

Kata Kunci: Kekayaan Intelektual, Hasil Penelitian, Strategi, Pendidikan Biologi 


\section{PENDAHULUAN}

Perguruan Tinggi di Indonesia selama ini berperan sebagai institusi pendidikan dan pengajaran, institusi penelitian dan pengabdian pada masyarakat. Perguruan Tinggi memiliki tiga fungsi utama yakni pendidikan, penelitian dan mengembalikan hasil penelitian kepada masyarakat. Fungsi yang dimiliki Perguruan Tinggi tersebut diharapkan dapat menghasilkan sumber daya manusia yang terlatih dan terdidik dibidang ilmu pengetahuan, teknologi dan seni, sehingga dapat menghasilkan kekayaan intelektual.

Kekayaan Intelektual (KI) adalah hasil pemikiran berupa ide atau gagasan yang diwujudkan atau diekspresikan dalam bentuk penemuan, karya ilmu pengetahuan sastra dan seni, desain, simbol/tanda tertentu, kreasi tata letak komponen semikonduktor maupun varietas hasil pemuliaan (Mujiyono dan Ferianto, 2017).

Secara garis besar HKI dibagi dalam 2 (dua) bagian yaitu hak cipta (copyrights) dan hak kekayaan industri yang mencakup paten, desain industri, merek, penanggulangan praktek persaingan curang, desain tata letak sirkuti terpadu, dan rahasia dagang (Dirjen HKI, 2001).

Kekayaan intelektual menjadi sangat penting bagi Perguruan Tinggi karena dapat: 1) meningkatkan nilai akreditasi Perguruan Tinggi, 2) meningkatkan prestis inventor, Program Studi, Fakultas dan Universitas, 3) income bagi inventor dan lembaga serta 4) memperluas networking. Oleh karena itu Perguruan Tinggi harus terus mengembangkan dan menyebar luaskan ilmu pengetahuan, teknologi dan seni melalui berbagai aktivitas riset dan inovasi yang dilakukan.

Objek Kekayaan Intelektual berupa karya-karya di bidang ilmu pengetahuan, seni, sastra, ataupun teknologi yang dihasilkan oleh manusia dengan pengorbanan tenaga, waktu dan biaya. Adanya pengorbanan tersebut menjadikan karya yang dihasilkan menjadi memiliki nilai. Apabila ditambah dengan manfaat ekonomi yang dapat dinikmati, maka nilai ekonomi yang melekat menumbuhkan konsepsi kekayaan (Property) terhadap karyakarya intelektual (Klinik Konsultasi HKI, tanpa tahun).

HKI bagi perguruan tinggi itu sangat penting. Sebab bisa memperkuat akreditasi, proses akademik, pemberdayaan masyarakat, dan sumber informasi, serta menumbuhkan kebanggaan perguruan tinggi itu sendiri. Untuk mendorong peningkatan kekayaan intelektual sebuah Perguruan 
Tinggi dibutuhkan peran aktif berbagai pihak, yakni dosen dan mahasiswa.

Seluruh Dosen Program studi Pendidikan Biologi FKIP Universitas Tanjungpura sebagai bagian dari Perguruan Tinggi Universitas Tanjungpura memiliki tugas dalam melaksanakan Tri Dharma Perguruan Tinggi. Bentuk Tri Dharma tersebut diwujudkan dengan melaksanakan penelitian dan Pengabdian pada masyarakat. Penelitian dan pengabdian pada masyarakat dilaksanakan oleh dosen setiap tahun baik secara mandiri maupun berkelompok. Pelaksanaan penelitian dan pengabdian ada yang menggunakan dana mandiri, anggaran DIPA Fakultas, maupun dana Kemenristekdikti (Penelitian Kompetitif Nasional). Bahkan untuk membantu peningkatan akreditasi Program Studi, beberapa dosen Program studi Pendidikan Biologi juga membuat payung penelitian dengan melibatkan mahasiswa-mahasiswa yang sedang menyusun tugas akhir (skripsi).

Banyaknya penelitian dan pengabdian pada masyarakat yang dilakukan oleh dosen dan mahasiswa Program Studi Pendidikan Biologi FKIP Universitas Tanjungpura setiap tahun juga berdampak pada banyaknya hasil penelitian dan pengabdian pada masyarakat yang dicapai dan proses yang dilakukan.

Dari penelitian dan pengabdian pada masyarakat yang telah dilakukan oleh dosen dan mahasiswa dihasilkan proses serta produk / temuan baru dalam bidang biologi maupun pembelajaran biologi seperti bahan ajar dan media pembelajaran.

Selama ini luaran dari hasil penelitian dan pengabdian kepada masyarakat yang dihasilkan oleh dosen dan mahasiswa Program studi pendidikan biologi berupa publikasi dalam bentuk artikel yang diseminarkan maupun diterbitkan dalam jurnal ilmiah. Hanya beberapa yang luaran tersebut dijadikan sebagai hasil Kekayaan Intelektual (KI) dan jumlahnyapun sangat sedikit. Padahal hasil penelitian dan dan pengabdian pada masyarakat tersebut bisa menjadi kekayaan intelektual (KI) yang berharga dan memiliki nilai penting.

Saat ini hanya beberapa dosen dan mahasiswa di program studi Pendidikan Biologi FKIP Universitas Tanjungpura yang memiliki kekayaan intelektual baik berupa paten maupun hak cipta, itupun jumlahnya sangat sedikit. Dari hasil wawancara dengan dosen dan mahasiswa diperoleh informasi bahwa 
masih banyak yang belum memiliki pengetahuan mengenai proses pengajuan kekayaan intelektual.

Untuk itu perlu dicari alternatif dalam rangka penguatan inovasi, hilirisasi riset, dan pemanfaatan hasil riset/pengabdian masyarakat berpotensi sebagai kekayaan intelektual (KI) tersebut, agar dapat menjadi aset yang berharga bahkan dilindungi oleh negara serta dapat meningkatkan indeks kekayaan intelektual Perguruan Tinggi dan memperoleh nilai maksimal pada akreditasi Program Studi Pendidikan Biologi FKIP Universitas Tanjungpura. Salah satu alternatif tersebut adalah melalui kegiatan penyusunan dan pengajuan Kekayaan Intelektual.

\section{METODE PELAKSANAAN}

Kegiatan Pengabdian Kepada Masyarakat (PKM) ini dilaksanakan di aula FKIP Universitas Tanjungpura Pontianak pada tanggal 8 Juli 2019. Peserta kegiatan adalah dosen dan mahasiswa Program Studi Pendidikan Biologi FKIP Universitas Tanjungpura. Kegiatan ini menghadirkan pemateri yang sekaligus sebagai ketua HKI Universitas Tanjungpura yakni Dr. Ir. Yohana Sutiknyawati Kusuma Dewi M.P.
Kegiatan ini dilakukan dengan dengan dua metode yaitu:

a. Sosialisasi

Pemberian sosialisasi kepada dosen dan mahasiswa Program Studi Pendidikan Biologi FKIP Universitas Tanjungpura mengenai berbagai jenis kekayaan intelektual (KI) serta manfaat yang dapat diperoleh dengan adanya kekayaan intelektual (KI).

b. Pendampingan/workshop Kegiatanpendampingan/workshop kepada dosen dan mahasiswa Program Studi Pendidikan Biologi FKIP Universitas Tanjungpura yang dilakukan langsung oleh Ketua HKI Universitas Tanjungpura tentang tata cara pengajuan atau pengusulan kekayaan intelektual (KI).

c. Pemberian angket respon

Pemberian angket respon kepada mahasiswa dan dosen. Sejalan dengan pernyataan Suriyanti dan Thoharuddin (2019) evaluasi terhadap pelaksanaan PKM dapat secara langsung dilakukan pelaksana yakni melalui pemberian angket.

\section{HASIL DAN PEMBAHASAN}

Kegiatan PKM Program Studi Pendidikan Biologi dengan tema strategi penyusunan dan pengajuan hak kekayaan intelektual yang dilaksanakan berjalan dengan lancar. Rangkaian 
pelaksanaan kegiatan pelatihan dimulai dengan pembukaan oleh pembawa acara. Setelah kegiatan dibuka para peserta diminta untuk berdiri dan bersama-sama menyanyikan lagu wajib Indonesia Raya.

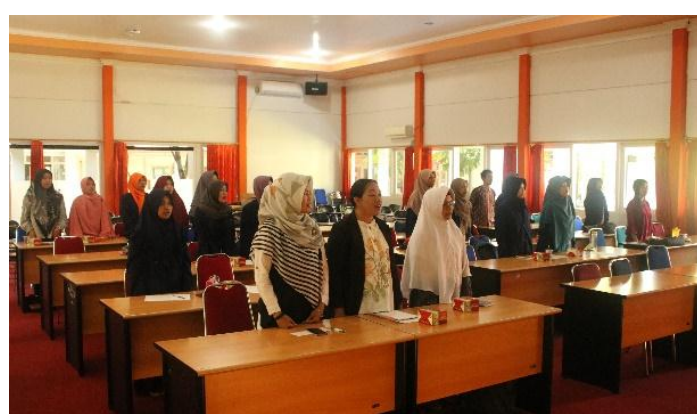

Gambar 1. Peserta Pelatihan Menyanyikan Lagu Indonesia Raya

Kegiatan selanjutnya adalah laporan dari ketua panitia PKM yaitu Titin, M,Pd (Gambar 2).

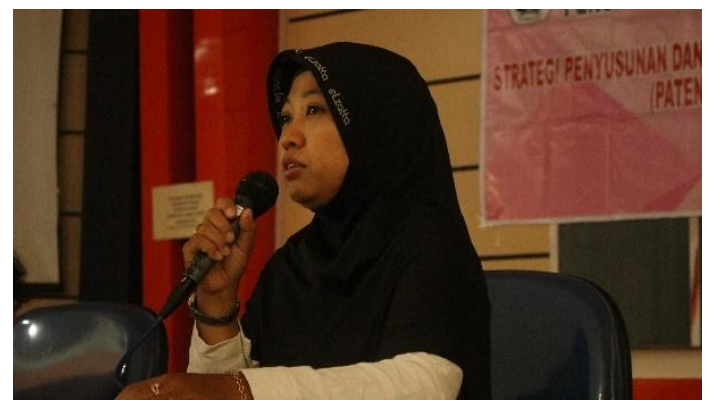

Gambar2. Laporan Ketua Panitia

Kegiatan dilanjutkan dengan penyampaian kata sambutan sekaligus pembukaan kegiatan PKM oleh Wakil dekan II FKIP Universitas Tanjungpura Dr. Hairida, M.Pd (Gambar 3).

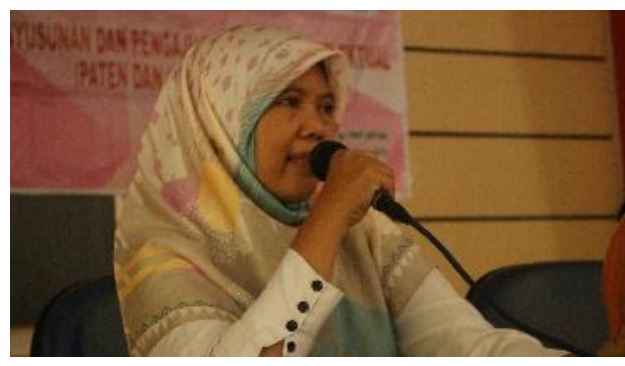

Gambar 3. Pembukaan Kegiatan

Kegiatan pembukaan diakhiri dengan pembacaan doa yang dipimpin oleh salah satu peserta kegiatan (Gambar 4).

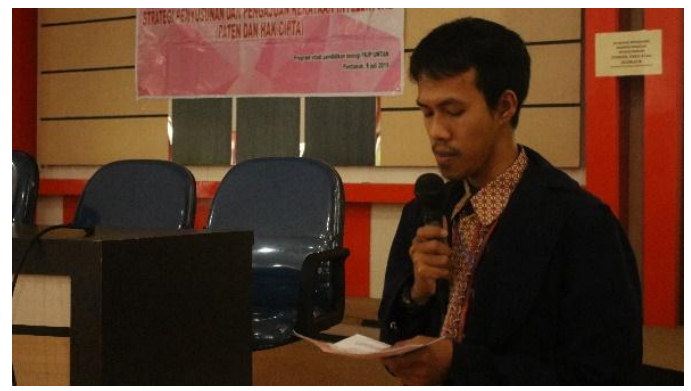

Gambar 4. Pembacaan Doa

Sosialisasi dan pendampingan strategi penyusunan dan pengajuan hak kekayaan intelektualyang disampaikan oleh pemateri berisi mengenai pengetahuan dan tata cara pengajuan kelayakan intelektual (Gambar 5).

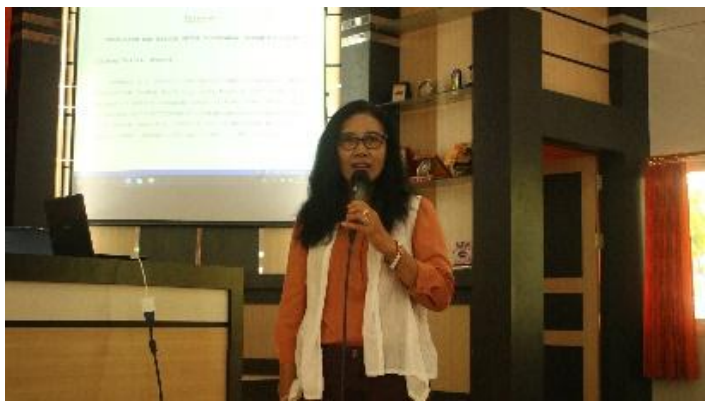

Gambar 5. Penyampaian Materi 
Kegiatan sosialisasi dan pendampingan ini menjadi sangat penting agar peserta kegiatan baik dosen maupun mahasiswa memiliki pengetahuan dan informasi serta kesadaran untuk memberikan perlindungan terhadap hasil penelitian dan pengabdian yang telah diperolehnya. Hal ini sejalan dengan pernyataan Anonim(2007) bahwa kegiatan sosialisasi dan penyuluhan terkait Hak Kekayaan Intelektual harus terprogram dengan baik bagiberbagai pihak masih perlu terus ditingkatkan dengan tujuan meningkatkan pengetahuan dan wawasan peserta pelatihan dalam peraturan-peraturan, hukum yang berlaku serta sanksi-sanksi dalam penerapan hak kekayaan inteletual. Selain itu juga agar peserta mengetahui prosedur penerapan, masalah yang dihadapi dalam pelaksanaan serta termotivasi untuk menciptakan hal-hal baru.

Dalam kegiatan pendampingan, peserta terlihat sangat antusias dan serius dalam mendengarkan paparan yang disampaikan oleh pemateri. Terlihat pada sesi tanya jawab cukup banyak peserta yang mengajukan pertanyaan baik terkait informasi yang ingin mereka ketahui ataupun prosedur yang harus mereka lakukaan saat mengajukan kekayaan intelektual (Gambar 6 dan 7).

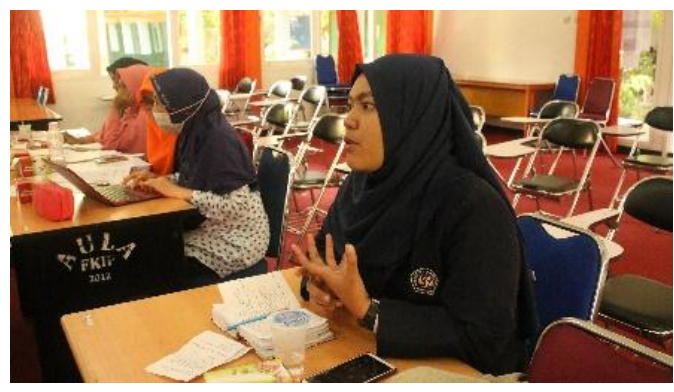

Gambar 6. Mahasiswa Mengajukan Pertanyaan

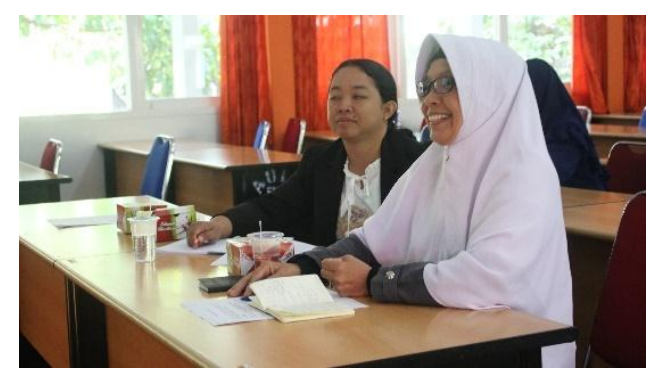

\section{Gambar 7. Dosen Mengajukan Pertanyaan}

Selesai kegiatan pengabdian kepada masyarakat dilaksanakan, dibagikan angket kepada dosen mahasiswa, Adapun hasil yang didapat seperti pada Tabel 1. 
Tabel 1. Angket Respon Mahasiswa

\begin{tabular}{|l|l|c|c|}
\hline No & \multicolumn{1}{|c|}{ Pernyataan } & \multicolumn{2}{c|}{ Presentase (\%) } \\
\cline { 3 - 4 } & & Dosen & Mahasiswa \\
\hline 1 & $\begin{array}{l}\text { Pernah mendengar istilah kekayaan intelektual sebelum } \\
\text { kegiatan dilaksanakan }\end{array}$ & 100 & 33,33 \\
\hline 2 & $\begin{array}{l}\text { Mendapatkan informasi jenis-jenis kekayaan intelektual } \\
\text { sebelum kegiatan dilaksanakan }\end{array}$ & 87,50 & 16,67 \\
\hline 3 & $\begin{array}{l}\text { Pernah mendapatkan sosialisasi mengenai KI (kekayaan } \\
\text { Intelektual) sebelum kegiatan dilaksanakan }\end{array}$ & 50 & 0 \\
\hline 4 & $\begin{array}{l}\text { Pernah mencoba mengajukan KI (Kekayaan Intelektual) } \\
\text { dari hasil penelitian yang diajukan sebelumnya }\end{array}$ & 37,50 & 0 \\
\hline 5 & $\begin{array}{l}\text { Mengajukan KI (Kekayaan Intelektual) secara mandiri } \\
\text { sebelumnya }\end{array}$ & 12,5 & 0 \\
\hline 6 & Pernah memperoleh KI (Kekayaan Intelektual) & 25 & 0 \\
\hline 7 & $\begin{array}{l}\text { Apakah pelatihan KI (Kekayaan Intelektual) yang } \\
\text { dilakukan bermanfaat }\end{array}$ & 100 & 100 \\
\hline 8 & $\begin{array}{l}\text { Rencana pengajuan KI (Kekayaan Intelektual) secara } \\
\text { mandiri setelah mengikuti pelatihan }\end{array}$ & 50 & 88,89 \\
\hline
\end{tabular}

Adapun hasil analisis dari angket tersebut diperoleh informasi sebelum pelaksanaan kegiatan, seluruh dosen Program studi Pendidikan Biologi yang mengikuti pelatihan pernah mendengar istilah kekayaan intelektual serta sebagian besar $87,50 \%$ sudah mengetahui jenis-jenis kekayaan intelektual. Sedangkan mahasiswa sebelum kegiatan ini dilakukan hanya sebesar 33,33\% yang pernah mendengar istilah kekayaan intelektual. Hal ini dapat dikatakan bahwa sebagian besar mahasiswa belum pernah mendengar istilah kekayaan intelektual.

Pada pernyataan ketiga dan keempat didapat informasi sebesar 50\% dosen pernah mendapatkan sosialisasi sebelumnya, dan 37,50\% bahkan sudah pernah mengajukan kekayaan intelektual dari hasil penelitian yang dilakukan.
Beberapa dosen yang belum pernah mengajukan kekayaan intelektual memberikan alasan antara lain belum mengetahui cara pendaftaran KI, belum paham cara menyusun dokumen paten, tidak ada hasil/inovasi baru yang diperoleh dari hasil penelitian yang dilakukan, dan penelitian masih dalam tahap awal.

Berbeda dengan mahasiswa, hampir seluruh mahasiswa yang mengikuti pelatihan belum pernah mendapat sosialisasi mengenai kekayaan intelektual. Tentunya ini menjadi informasi yang sangat penting dan baru bagi mahasiswa.

Pada pernyataan kelima, diketahui hanya $12,5 \%$ dosen yang mengikuti pelatihan selama ini mengajukan KI secara mandiri, dalam proses pengajuan masih ada yang meminta bantuan orang 
lain untuk proses pengurusannya. Dari pernyataan ke enam, sebesar $25 \%$ dosen sudah pernah memperoleh kekayaan intelektual. Sedangkan mahasiswa yang mengikuti pelatihan belum pernah ada yang mengajukan dan memperoleh Kekayaan Intelektual.

Beberapa peserta yang belum pernah mengajukan kekayaan intelektual dan belum pernah memperoleh $\mathrm{KI}$ dikarenakan belum adanya informasi yang luas mengenai KI, padahal pengajuan KI memiliki tata cara yang mudah dan memiliki tujuan yang sangat penting. Menurut Alfiani (2012) Kekayaan intelektual (KI) bertujuan untuk melindungi para pencipta dan prosedur barang dan jasa intelektual lainnya melalui pemberian hak tertentu secara terbatas untuk mengontrol penggunaan yang dilakukan produser tersebut. Pernyataan kedelapan terdapat presentase sebesar $100 \%$ hal ini dapat dikatakan bahwa pelatihan yang diberikan kepada peserta banyak memberi manfaat. Menurut Mastur (2012) menyatakan dengan adanya perlindungan HKI maka ada jaminan kepada masyarakat untuk menghargai hak inisiatif dan rekasi serta memberikan perlindungan akan hasil karya ciptanya.

Dengan ini sangat penting untuk memberikan perlindungan suatu produk yang telah dibuat sehingga tidak dapat disalahgunakan. Pada pernyataan ketujuh seluruh peserta pelatihan baik dosen maupun mahasiswa menyatakan bahwa kegiatan pelatihan yang dilaksanakan ini sangat bermanfaat. Bahkan dari pernyataan kedelapan diperoleh informasi sebagian peserta berencana untuk mengajukan KI (Kekayaan Intelektual)secara mandirisetelah mengikuti pelatihan.

\section{SIMPULAN}

Pada kegiatan ini telah dilakukan sosialisasi dan pendampingan strategi penyusunan dan pengajuan kekayaan intelektual kepada dosen dan mahasiswa Program Studi Pendidikan Biologi FKIP Universitas Tanjungpura. Kegiatan PKM yang dilakukan mendapatkan respon positif dari peserta. Seluruh peserta menyatakan kegiatan ini sangat bermanfaat dan memberikan informasi tata cara pengajuan kekayaan intelektual.

\section{UCAPAN TERIMAKASIH}

Ucapan terima kasih ditujukan kepada:

1. Ketua Lembaga Penelitian dan Pengabdian Kepada Masyarakat Universitas Tanjungpura yang telah memberikan ijin pelaksanaan kegiatan. 
2. Dekan FKIP Universitas

Tanjungpura yang telah memberikan dana melalui DIPA Fakultas dan memberikan ijin pelaksanaan kegiatan.

\section{DAFTAR RUJUKAN}

Alfiani, Reni. 2012. Hak Kekayaan Intelektual Di Bidang Hak Cipta Paten dan Merek. Fakultas Komputer UAS-88675543.

Anonim. 2007. Kebijakan Pemerintah Dalam Perlindungan Hak Kekayaan Intelektual Dan Liberalisasi Perdagangan Jasa Profesi Di Bidang Hukum. Jakarta. Direktorat Jenderal Industri Kecil dan Menengah Departemen Perindustrian

Dirjen Hak Kekayaan Intelektual. 2001.

Undang-undang No. 14 Tahun 2001 Tentang Paten. Jakarta: Direktorat Jendral Hak Kekayaan Intelektual, Departemen Kehakiman dan Hak Asasi Manusia Republik Indonesia.

Klinik Konsultasi HKI. Tanpa Tahun. Panduan Pengenalan HKI (Hak Kekayaan Intelektual). Jakarta: Direktorat Jenderal Industri Kecil dan Menengah

Mastur. 2012. Perlindungan Hukum Hak Kekayaan Intelektual Di Bidang Paten.Jurnal Ilmiah Ilmu Hukum QISTI 6 (1) Hal 65-81

Mujiyono dan Ferianto. 2017. Buku Praktis Memahami dan Cara Memperoleh Hak Kekayaan Intelektual. Yogyakarta: Sentra KI Universitas Negeri Yogyakarta
Suriyanti, Yulia dan Thoharuddin, Munawar. 2019. Media Pembelajaran IPS Bagi Guru Anggota MGMP IPS Kabupaten Sintang. Jurnal Pengabdian Masyarakat Khatulistiwa. 2(1) Hal 1-9 